\title{
Ultrasonography for the Diagnosis of Intussusception in Children: An Experience From Pakistan
}

\author{
Arthina Dadlani ${ }^{1}$, Sajan Lal ${ }^{1}$, Bhesham Shahani ${ }^{1}$, Muhammad Ali ${ }^{1}$ \\ 1. Radiology, Dr. Ziauddin Hospital, Karachi, PAK
}

Corresponding author: Arthina Dadlani, arthworm@gmail.com

\begin{abstract}
Introduction: Intussusception can lead to small bowel obstruction in children, hence the early diagnosis of this condition is very important. The purpose of this study is to evaluate the accuracy of sonography in the diagnostic work-up of children with suspected intussusceptions in the emergency setting, keeping surgical findings as the gold standard.
\end{abstract}

Methods and design: Two hundred patients with classical presentation of intussusceptions, who were diagnosed either by barium enema or CT scan, were included in this study. Patients with irreducible intussusceptions on color Doppler were followed after surgery.

Results: The average age of the patients was $6.7 \pm 2.8$ years, and the study population consisted of 115 (57.5\%) boys and 85 (42.5\%) girls. One hundred forty-three patients were confirmed to have intussusception on ultrasonography, of whom 117 (81.8\%) were confirmed to have intussusception after surgery while 26 (18\%) were not diagnosed with intussusception during surgery. Despite the clinical presentation of intussusceptions, ultrasonography was not diagnostic in 57 patients, of whom 28 were confirmed to have intussusception after surgery and 29 were not found to have the disease.

Conclusion: Use of ultrasonography in cases with intussusception has proven to be a reliable and accurate method for diagnosing intussusception and provides an advantage over unnecessary radiological or surgical procedures being performed.

Received 06/28/2020

Review began $07 / 22 / 2020$ Review ended 08/08/2020 Published 08/11/2020

\section{() Copyright 2020}

Dadlani et al. This is an open access article distributed under the terms of the Creative Commons Attribution License CC-BY 4.0., which permits unrestricted use, distribution, and reproduction in any medium, provided the original author and source are credited.
Categories: Radiology

Keywords: intussusception, ultrasonography, bowel obstruction

\section{Introduction}

Intussusception is a common cause of children requiring admission to the emergency department and can lead to bowel obstruction. Intussusception occurs when a segment of the bowel invaginates into an immediately adjacent segment, often likened to a telescope, resulting in obstruction of the bowel, ischemia, and necrosis $[1,2]$. Five types of intussusceptions are described: ileo-colic, ileo-ileo-colic, jejunojejunal, jejuno-ileal, and colo-colic. Ileo-colic intussusception is the most common type, accounting for over $80 \%$ of cases in children [3].

Most of the symptoms are due to obstruction of the bowel and consist of a classic triad of abdominal colic, bile-stained vomiting, and red jelly stools. This triad of intermittent symptoms has a positive predictive value of $93 \%$. Adding the symptom of rectal bleeding to this triad raises the positive predictive value to $100 \%$ [4].

Intussusceptions are one of the most common causes of bowel obstruction in infancy. It can lead to intestinal necrosis, bowel resection, and even death if not recognized and treated appropriately. Intussusception seems to be idiopathic in $90 \%$ of cases and is associated with pathologic lead points such as Meckel's diverticulum, solid bowel lesion, and intestinal lymphoma [5-6]. It can occur postoperatively and after blunt abdominal trauma [7].

Intussusception in infants occurs at 0.3 to 2.7 cases per 1,000 live births in Europe, North America, and Australia [8-9]. However, the incidence rate is higher in some developing countries, which leads to a higher rate of complications in those areas [10].

A diagnostic enema may be the most cost-effective method of excluding or confirming the diagnosis, particularly when air enema is used. Most children presenting with classic features of intussusceptions should undergo air enema directly to avoid duplication of investigation.

CT is a reliable method for diagnosing intussusception in adults. Abdominal radiographs should be reserved 
for children with clinical evidence of peritonitis and possible perforation, an atypical clinical presentation, or equivocal ultrasonography findings.

Abdominal ultrasonography is an excellent screening test for children with non-classical clinical features. Ultrasonography screening has been suggested to reduce cost, radiation exposure, and anxiety/discomfort of patients and parents. Published literature suggests high accuracy, approaching 100\% in experienced hands, with sensitivity of $98 \%$ to $100 \%$ and specificity of $88 \%$ to $100 \%$ [11]. Additionally, ultrasonography helps in identifying alternative diagnoses as well as the evaluation of reducibility of an intussusception, the presence of a lead point mass, and intussusception limited to the small bowel [12,13].

The advantages of ultrasonography are that it allows noninvasive, rapid, and confident diagnosis with lack of ionizing radiation as compared to barium enema. It can be done bedside, even with less experienced readers.

Due to a scarcity of literature with relevant data, our aim is to present the available data at our center. The purpose of this study is to evaluate the accuracy of ultrasonography in the diagnostic work-up of children suspected of intussusception in the emergency setting, keeping surgical findings as the gold standard.

\section{Materials And Methods}

With approval from the Clinical Research Committee and Ethics Review Committee of Ziauddin University, we performed a retrospective review of the electronic medical records of 200 patients fulfilling the inclusion criteria from 31/08/2017 to 01/03/2018. Patients were included from inpatient, outpatient, and emergency department of Dr. Ziauddin Hospital. Inclusion criteria considered were: patients with suspicion of intussusception presenting with a clinical triad of colicky abdominal pain, vomiting, and red jelly stools, and children below 12 years of age of either sex.

Informed consent was taken from the parents over the phone to include the patient's data, and a brief medical history regarding duration and symptoms of intussusceptions was sought. All information gathered during this study was kept confidential.

All ultrasonography images were reviewed from the saved data. Ultrasonography was performed using probes of 3.5 MHz and 8.0 MHz on a Toshiba Aplio machine (Toshiba, Tokyo, Japan). Serial longitudinal and transverse images were taken and assessed by a senior attending radiologist with three years of experience in radiology. All patients diagnosed as having signs of irreducible intussusceptions, such as free fluid or absent blood flow on color Doppler, were followed after surgery. Those cases in which barium enema failed to reduce the intussusception, making surgery the ultimate treatment, were also included. Patients' findings (positive or negative) were collected and documented on a proforma attached with annexure.

\section{Data analysis procedure}

Patients' data were collected and analyzed through SPSS for Windows, Version 16.0 (SPSS Inc., Chicago, USA). Patients' ages were presented by mean \pm SD. After analyzing the data, sensitivity, and specificity, negative and positive predictive values of ultrasonography for detecting intussusceptions were calculated by taking surgical findings as the gold standard. Kappa analysis was also performed to measure the degree of agreement between surgical and ultrasonography findings, and a p-value less than 0.05 was considered significant.

\section{Results}

Two hundred patients with intussusception diagnosed on ultrasonography confirmed either by barium enema or CT scan were included in this study. The average age of the patients was $6.7 \pm 2.3$ years (Table 1 ). There were 115 (57.5\%) boys and 85 (42.5\%) girls. 


\section{Cureus}

\section{Demographics}

Mean age (Years)

$6.7 \pm 2.8$

Male

115

Female

85

Ultrasonography positive

143

Ultrasonography negative

57

TABLE 1: Descriptive statistics of age

The rate of intussusception in children was $72.5 \%$ (145/200) confirmed after surgery while ultrasonography reported $71.5 \%$ (143/200) of patients with intussusception. Similarly, true-positive, true-negative, falsepositive, and false-negative findings are reported in Table 2.

\begin{tabular}{|c|c|c|c|}
\hline \multirow{2}{*}{ Ultrasonography } & \multicolumn{2}{|c|}{ Surgical Findings } & \multirow{2}{*}{ Total } \\
\hline & Positive & Negative & \\
\hline Positive & 117 (TP) & 26 (FP) & 143 (71.5\%) \\
\hline Negative & $28(\mathrm{FN})$ & $29(\mathrm{TN})$ & 57 (28.5\%) \\
\hline Total & 145 (72.5\%) & 55 (27.5\%) & 200 \\
\hline
\end{tabular}

TABLE 2: Ultrasonography and surgical findings in the diagnostic work-up of children with suspected intussusception

Sensitivity, specificity, positive predictive value, negative predictive value, and accuracy of ultrasonography in detection of intussusception in children were $80.7 \%$ (95\%CI: 73.5 to 86.3 ), $52.7 \%$ ( $95 \%$ CI: 39.79 to 65.31 ), $81.8 \%$ (95\% CI: 74.7 to 87.3 ), $50.9 \%$ (95\% CI: 38.3 to 63.4 ), and $73 \%$ (95\%CI: 66.46 to 78.68 ), respectively, as shown in Table 3. Agreement was also observed that kappa statistics $(\mathrm{k}=0.33 ; \mathrm{p}=0.005)$ showed the weak agreement between ultrasonography and surgical findings (Table 3).

\begin{tabular}{|l|l|l|}
\hline Parameter & Estimate & $95 \% \mathrm{Cl}$ \\
\hline Sensitivity & $80.7 \%$ & 73.5 to 86.3 \\
\hline Specificity & $52.7 \%$ & 39.79 to 65.31 \\
\hline Positive predictive value & $81.8 \%$ & 74.7 to 87.3 \\
\hline Negative predictive value & $50.9 \%$ & 38.3 to 63.4 \\
\hline Diagnostic accuracy & $73 \%$ & 66.46 to 78.68 \\
\hline Cohen's kappa (unweighted) & 0.33 & 0.19 to 0.47 \\
\hline
\end{tabular}

TABLE 3: Diagnostic accuracy of sonography in the diagnostic work-up of children with suspected intussusception in the emergency setting, keeping surgical findings as the gold standard

Diagnosis of intussusception was made with ultrasonography in 143 patients (71.5\%), of whom 117 (81.8\%) were confirmed to have intussusception after surgery while $26(18 \%)$ were not diagnosed during surgery. Despite the clinical presentation of intussusception, ultrasonography was not diagnostic in 57 patients, of whom 28 were confirmed to have intussusception after surgery and 29 were not found to have the disease. 


\section{Cureus}

Furthermore, data was analyzed separately in males and females. As shown in Figure 1, the ratio of males $(88,44 \%)$ diagnosed with ultrasonography was higher than females (55, 28\%).
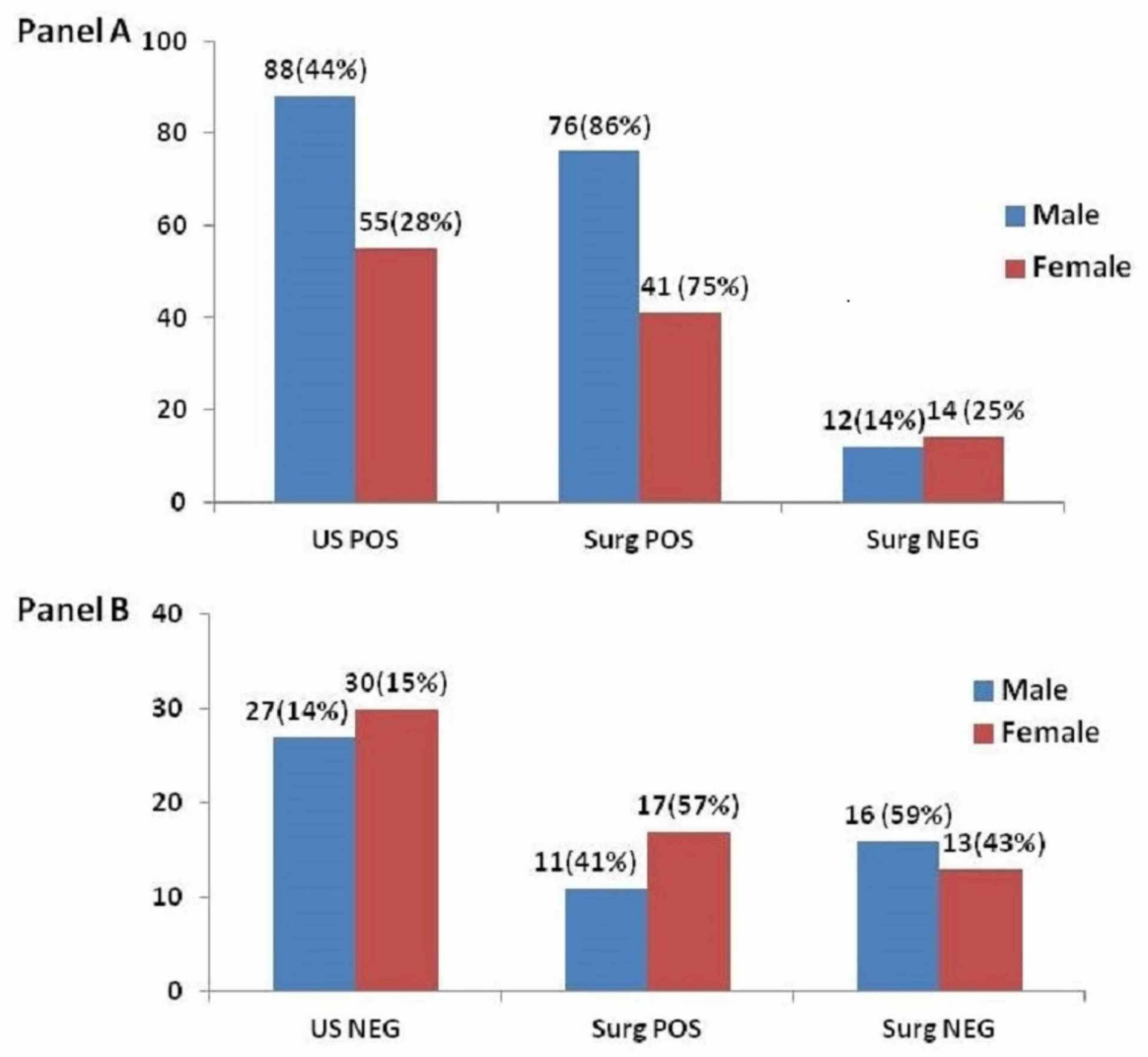

FIGURE 1: Distribution of intussusception in males and females (A) surgical confirmed (positive) and unconfirmed (negative) after intussusception diagnosed with US (US positive), (B) surgical confirmed (positive) and unconfirmed (negative) after ultrasonography was negative for intussusception (US negative)

US pos: Ultrasound positive; US neg: Ultrasound negative; Surg pos: Surgery positive; Surg neg: Surgery negative

\section{Discussion}

The traditional investigations with small bowel enteroclysis and small bowel follow-through do not provide much information and unfortunately involve radiation exposure of the patient. Although it is an organ that is spared from frequent disease, more precise and patient-friendly methods are needed [14]. Recent advances in new imaging techniques, including CT, MRI, wireless capsule endoscopy, and double-balloon endoscope, have proven to be useful in diagnosing intussusception.

Ultrasonography is accurate and more affordable compared to other diagnostic modalities for intussusception; however, due to its dependency on operative experience, its reliability in diagnosing intussusception has been debated among radiologists. [15]. Ultrasonography is the primary imaging modality for initial diagnosis in developing countries. Ultrasonography also plays a role in the identification of alternative diagnoses, as well as the evaluation of reducibility of an intussusception, the presence of a lead point mass, and intussusception limited to the small bowel. Studies have shown that ultrasonography can lead to accurate (100\%) diagnosis with experienced operators [13-16]. The advantages of ultrasonography are that it allows non-invasive, rapid, and confident diagnosis with lack of ionizing radiation as compared to CT scan and barium enema. It can be done bedside even with less experienced readers. It also helps to determine whether the involved bowel should be reduced non-operatively or surgically resected. Inability to detect blood flow in the intussusception predicts the need for surgery.

In this study, the average age of the patients was $6.69 \pm 2.27$ years. There were $115(57.5 \%)$ boys and 85 (42.5\%) girls. In the Gul et al. study [17], $56.8 \%$ were boys, and $43.2 \%$ were girls. The boy to girl ratio was 
In this study, sensitivity, specificity, positive predictive value, negative predictive value, and accuracy of ultrasonography in the detection of intussusception in children were $80.7 \%$ (95\% CI: 73.5 to 86.3 ), $52.7 \%$ (95\% CI: 39.8 to 65.3 ), $81.8 \%$ (95\% CI: 74.7 to 87.3 ), $50.88 \%$ (95\% CI: 38.3 to 63.4 ), and $73 \%$ (95\% CI: 66.5 to 78.7), respectively. In our study, sensitivity in diagnosing intussusception was similar to other studies; however, specificity was low compared to available literature, likely due to operator experience, equipment availability, and urgent situations in which ultrasonography was performed.

In Gul et al., the overall sensitivity of ultrasonography in the detection of intussusception was $83.9 \%$, specificity was $95.7 \%$, and accuracy was $93.7 \%$ [17]. A large-scale prospective study reported that ultrasonography is $97.5 \%$ sensitive and $99 \%$ specific for the diagnosis of acute intussusception in children in developing countries, despite the use of equipment that was older than what is generally available in developed countries.

Ultrasonography is also useful in observing transient intussusception or spontaneous reduction obviating the need for enema reduction. Additionally, presence of other conditions including small bowel volvulus, necrotizing enterocolitis, and urinary tract disease can be detected with the help of ultrasonography at the same time [18-20].

Early diagnosis of intussusception with ultrasonography as an initial screening test will decrease the unnecessary radiation exposure with contrast-based enemas if ultrasonography is negative for intussusception. This may result in greater cost as a positive diagnosis on ultrasonography will subsequently require contrast enema as well.

\section{Conclusions}

In our study, ultrasonography was shown to be sensitive and accurate in diagnosing intussusception. It is a safe and valuable clinical tool in the diagnosis of acute intussusception in children due to its absence of radiation, non-invasiveness, and rapid nature. Additionally, our data can set the stage for physicians to confidently use ultrasonography in patients clinically suspicious for intussusception as the initial imaging modality over unnecessary radiological or surgical procedures, given its cost-effectiveness as well.

\section{Additional Information \\ Disclosures}

Human subjects: Consent was obtained by all participants in this study. Animal subjects: All authors have confirmed that this study did not involve animal subjects or tissue. Conflicts of interest: In compliance with the ICMJE uniform disclosure form, all authors declare the following: Payment/services info: All authors have declared that no financial support was received from any organization for the submitted work. Financial relationships: All authors have declared that they have no financial relationships at present or within the previous three years with any organizations that might have an interest in the submitted work. Other relationships: All authors have declared that there are no other relationships or activities that could appear to have influenced the submitted work.

\section{References}

1. Tareen F, Mc Laughlin D, Cianci F, Hoare SM, Sweeney B, Mortell A, Puri P: Abdominal radiography is not necessary in children with intussusception. Pediatr Surg Int. 2016, 32:89-92. 10.1007/s00383-015-3817-6

2. Vujovic D, Lukac M, Sretenovic A, Krstajić T, Ljubić V, Sinđić-Antunović S: Indications for repeated enema reduction of intussusception in children. Srp Arh Celok Lek. 2014, 142:320-4. 10.2298/SARH1406320V

3. Williams H: Imaging and intussusception. Arch Dis Child Educ Pract Ed. 2008, 93:30-6. 10.1136/adc.2007.134304

4. Ko HS, Schenk JP, Troger J, Rohrschneider WK: Current radiological management of intussusception in children. Eur Radiol. 2007, 17:2411-21. 10.1007/s00330-007-0589-y

5. Ein SH: Leading points in childhood intussusception . J Pediatr Surg. 1976, 11:209-211. 10.1016/00223468(76)90289-x

6. Applegate KE: Intussusception in children: evidence-based diagnosis and treatment. Pediatr Radiol. 2009, 39:140-143. 10.1007/s00247-009-1178-9

7. Altuntas N, Boyunaga O, Karabulut R, et al.: Ileo-ileal intussusception in a premature neonate: an unusual cause of NEC in premature babies. J Coll Physicians Surg Pak. 2015, 25:76-7.

8. Justice FA, Auldist AW, Bines JE: Intussusception: trends in clinical presentation and management . Gastroenterol Hepatol. 2006, 21:842-846. 10.1111/j.1440-1746.2005.04031.x

9. Fiegel H, Gfroerer S, Rolle U: Systematic review shows that pathological lead points are important and frequent in intussusception and are not limited to infants. Acta Paediatr. 2016, 105:1275-1279. 10.1111/apa.13567

10. Lehnert T, Sorge I, Till H, Rolle U: Intussusception in children--clinical presentation, diagnosis and management. Int J Colorectal Dis. 2009, 24:1187-92. 10.1007/s00384-009-0730-2

11. Harrington L, Connolly B, Hu X, Wesson DE, Babyn P, Schuh S: Ultrasonographic and clinical predictors of intussusception. J Pediatr. 1998, 132:836-839. 10.1016/S0022-3476(98)70314-2 


\section{Cureus}

12. Applegate KE: Clinically suspected intussusception in children: evidence-based review and self-assessment module. AJR Am J Roentgenol. 2005, 185:175-83. 10.2214/ajr.185.3_supplement.0185s 175

13. Justice FA, de Campo M, Liem NT, Son TN, Ninh TP, Bines JE: Accuracy of ultrasonography for the diagnosis of intussusception in infants in Vietnam. Pediatr Radiol. 2007, 37:195-9. 10.1007/s00247-006-0381-1

14. Bines JE, Ivanoff B, Justice F, Mulholland K: Clinical case definition for the diagnosis of acute intussusception. J Pediatr Gastroenterol Nutr. 2004, 39:511-8.

15. World Health Organization: Report of the Meeting on Future Directions for Rotavirus Vaccine Research in Developing Countries, Geneva, 9-11 February 2000. WHO, Geneva; 2000.

16. Hryhorczuk AL, Strouse PJ: Validation of US as a first-line diagnostic test for assessment of pediatric ileocolic intussusception. Pediatr Radiol. 2009, 39:1075-9. 10.1007/s00247-009-1353-z

17. Gul P, Mansoor MA, Mahmud R, Jesrani A, Zaidi SMH: The diagnostic accuracy of sonography in children suspecting intussusception keeping surgical findings as gold standard. PJR. 2016, 26:291-295.

18. Scalabre A, Demede D, Gaillard S, Pracros JP, Mouriquand P, Mure PY: Prognostic value of ultrasound grading systems in prenatally diagnosed unilateral urinary tract dilatation. J Urol. 2017, 197:1144-1149. 10.1016/j.juro.2016.11.103

19. Yang L, Xu W, Li YW, Yan CY: [Value of abdominal ultrasound in the diagnosis of neonatal necrotizing enterocolitis and evaluation of disease severity] (Article in Chinese). Zhongguo Dang Dai Er Ke Za Zhi. 2016, 18:108-112.

20. Lideo L, Roberto M: Predictors and ultrasonographic diagnosis of intussusception in children . Current Concepts in Colonic Disorders. Lule G (ed): InTech, Croatia; 2012. 23-46. 10.5772/25919 